\title{
Variance risk premia in energy commodities
}

\author{
Anders B. Trolle \\ Ecole Polytechnique Fédérale de Lausanne and Swiss Finance Institute \\ Eduardo S. Schwartz \\ UCLA Anderson School of Management and NBER
}

\begin{abstract}
This paper investigates variance risk premia in energy commodities, particularly crude oil and natural gas, using a robust model-independent approach. Over a period of 11 years, we find that the average variance risk premia are significantly negative for both energy commodities. However, it is difficult to explain the level and variation in energy variance risk premia with systematic or commodity specific factors. The return profile of a natural gas variance swap resembles that of a call option, while the return profile of a crude oil variance swap, if anything, resembles the return profile of a put option. The annualized Sharpe ratios from shorting energy variance are sizable; although not nearly as high as the annualized Sharpe ratio of shorting S\&P 500 index variance, they are comparable to those of shorting interest rate volatility or variance on individual stocks.
\end{abstract}

JEL Classification: G13

Keywords: Crude oil, natural gas, stochastic variance, risk premia

This version: November 2009

We thank Alejandro Balbas, Michael Brennan, Alvaro Cartea, Michel Crouhy, Peter Feldhütter, David Lando, Mads Stenbo Nielsen, Martin Richter, Tue Tjur, and seminar participants at Copenhagen Business School, Natixis, the Conference on Energy Finance at Kristiansand, and the Madrid Finance Workshop on for comments, and Joann Arena of NYMEX for making data available to us. Eduardo Schwartz: UCLA Anderson School of Management, 110 Westwood Plaza, Los Angeles, CA 90095-1481. E-mail: eduardo.schwartz@anderson.ucla.edu. Anders Trolle: Quartier UNIL-Dorigny, Extranef 216, CH-1015 Lausanne, Switzerland. E-mail: anders.trolle@epfl.ch. 


\section{Introduction}

Commodities are emerging as an asset class in their own right. The range of products offered to investors range from exchange traded funds (ETFs) to sophisticated products including principal protected structured notes on individual commodities or baskets of commodities and commodity range-accrual or variance swaps. More and more institutional investors are including commodities in their asset allocation mix and hedge funds are also increasingly active players in commodities; the most prominent example being Amaranth Advisors who lost in excess of USD 6 billion during September 2006 from trading natural gas futures contracts, leading to the fund's demise. ${ }^{1}$

Concurrent with these developments, a number of recent papers have examined the risk and return characteristics of investments in individual commodity futures or commodity indices composed of baskets of commodity futures - see, e.g., Erb and Harvey (2006), Gorton and Rouwenhorst (2006), Ibbotson (2006), and Kat and Oomen (2007a, 2007b). However, since all but the most plain-vanilla investments contain an exposure to volatility, it is equally important for investors to understand the risk and return characteristics of commodity volatilities. That is the purpose of this paper. More specifically, our aim is to understand variance risk premia in energy commodities, particularly crude oil and natural gas.

Our focus on energy commodities derives from two reasons. First, energy is the most important commodity sector, and crude oil and natural gas constitute the largest components of the two most widely tracked commodity indices: the Standard \& Poors Goldman Sachs Commodity Index (S\&P GSCI) and the Dow Jones-AIG Commodity Index (DJ-AIGCI). ${ }^{2}$ Second, our analysis is predicated upon the existence of a liquid options market, and crude oil and natural gas indeed have the deepest and most liquid options markets among all commodities.

The methodology used in this paper to quantify energy variance risk premia is similar to that used by Carr and $\mathrm{Wu}$ (2009) in their study of equity variance risk premia. The idea is to use variance swaps on futures contracts. At maturity, a variance swap pays off the difference between the realized variance of the futures contract over the life of the swap and the fixed variance swap rate. And since a variance swap has zero net market value at initiation, absence of arbitrage implies that the fixed variance swap rate equals the conditional risk-neutral expectation of the realized variance over the life of the swap. Therefore, the time-series average of the payoff and/or excess return on a variance swap is a measure of the variance risk premium. 
Variance swaps are over-the-counter products. For energy commodities, information on variance swap rates and their liquidity is not readily available. However, following theoretical advances in Carr and Madan (1998), Demeterfi, Derman, Kamal, and Zou (1999), BrittenJones and Neuberger (2000), Jiang and Tian (2005), and Carr and Wu (2009), it is possible to very accurately compute a synthetic variance swap rate from a cross-section of liquid exchangetraded options on futures contracts. Our study is based on daily data from January 2, 1996 until November 30, 2006 - a total of 2750 business days. ${ }^{3}$ The source of the data is NYMEX (the New York Mercantile Exchange), which is the largest marketplace for these options. ${ }^{4}$

The risk and return characteristics of equity index volatility has been studied in a number of papers - see, e.g., Coval and Shumway (2001), Pan (2002), Bakshi and Kapadia (2003a), Bondarenko (2004), Bollerslev, Gibson, and Zhou (2004), and Carr and Wu (2009). It is interesting to compare the results for energy commodities with the results reported in these papers. To facilitate a comparison based upon a common time-period, most analyses in the paper are also performed on the S\&P 500 index.

The main findings of the paper can be summarized as follows. First, the average variance risk premia are negative for both energy commodities but more strongly statistically significant for crude oil than for natural gas. This holds true whether variance risk premia are defined in dollar terms or in return terms. The annualized Sharpe ratios from shorting variance are sizable and larger for crude oil (0.59) than for natural gas (0.35), but not nearly as high as the annualized Sharpe ratio of shorting S\&P 500 index variance (1.02). Variance swap returns exhibit excess kurtosis and positive skewness in all three markets.

Second, it is well-known that natural gas variance exhibits strong seasonality and peaks during the cold months of the year. We show that the natural gas variance risk premium, whether defined in dollar terms or in return terms, is also higher during the cold months of the year, although the difference between the cold and the warm season is not statistically significant. The annualized Sharpe ratio of shorting natural gas variance is 0.38 during October to March compared with 0.35 during April to September.

Third, energy variance risk premia in dollar terms are time-varying and correlated with the level of the variance swap rate. In contrast, energy variance risk premia in return terms, particularly in the case of natural gas, are much less correlated with the (log) variance swap rate. This is similar to the dynamics of the S\&P 500 index variance risk premium.

Fourth, it is difficult to explain the level and variation in energy variance risk premia with systematic factors (returns on equity and commodity market portfolios) or commodity specific 
factors (inventories).

Fifth, in the case of natural gas and the S\&P 500 index, there is a strongly non-linear relationship between the log excess return on a variance swaps and the annualized log return on the underlying futures contracts over the lives of the swaps. However, while the return profile of a natural gas variance swap resembles that of a call option, the return profile of an S\&P 500 index variance swap resembles the return profile of a put option. The return profile of a crude oil variance swap has a less distinctive pattern, although if anything it also resembles the return profile of a put option.

Hence, a strategy of shorting natural gas variance performs qualitatively differently than a strategy of shorting S\&P 500 index variance in a number of important respects - the variance risk premium displays seasonality and the return profile resembles that of a call option rather than a put option - whereas a strategy of shorting crude oil variance performs qualitatively more similar to a strategy of shorting S\&P 500 index variance.

Many of the results for the S\&P 500 index variance risk premium reported in this paper are very similar to those reported in Carr and $\mathrm{Wu}$ (2009) and are only included here in order to benchmark the results for the energy variance risk premia. That paper also studies variance risk premia on selected individual stocks and finds that shorting variance generate annualized Sharpe ratios between 0 and $0.55 .^{5}$ Duarte, Longstaff, and $\mathrm{Yu}$ (2007) study volatility risk premia on interest rates and find that shorting interest rate volatility generate annualized Sharpe ratios between 0.47 and 0.82 . Therefore, while shorting crude oil and natural gas variance is not quite as attractive as shorting $\mathrm{S} \& \mathrm{P} 500$ index variance, the performance is comparable to shorting interest rate volatility or variance on individual stocks.

The methodology used in this paper has the advantage that it does not rely on a particular pricing model. Doran and Ronn (2008) estimate volatility risk premia for crude oil and natural gas using a parametric model. This makes their results conditional on the particular parametrization of the risk premium that they employ, and any misspecification will bias their results. Nevertheless, consistent with our results, they find that the average volatility risk premium is negative for both energy commodities.

The rest of the paper is organized as follows: Section 2 discusses the methodology for estimating variance risk premia, Section 3 reviews the data and various implementation issues, Section 4 presents the results, and Section 5 concludes. An Appendix contains technical details. 


\section{Estimating variance risk premia}

A variance swap is an instrument which allows investors to trade future realized variance of a given asset against current implied variance. At maturity, the variance swap pays off the difference between the realized variance of the reference asset over the life of the swap and the fixed variance swap rate. More specifically, the payoff at time $T$ of a variance swap for the period $t$ to $T$ is given by

$$
(V(t, T)-K(t, T)) L
$$

where $V(t, T)$ denotes the realized annualized return variance between time $t$ and $T, K(t, T)$ denotes the fixed variance swap rate, determined at time $t$, and $L$ denotes the notional of the swap. At initiation, the variance swap has zero net market value. Therefore, absence of arbitrage coupled with the assumption that interest rates are uncorrelated with realized variance, implies that the fixed variance swap rate is given by

$$
K(t, T)=E_{t}^{Q}[V(t, T)]
$$

That is, the fixed variance swap rate equals the conditional risk-neutral expectation of the realized variance over the life of the swap.

Let $F\left(t, T_{1}\right)$ denote the time- $t$ price of a futures contract maturing at time $T_{1}$ and suppose that $V(t, T)$ is given by the realized annualized continuously sampled futures return variance (i.e. the realized quadratic variation) over the period $[t, T], T \leq T_{1}$. Then, $K(t, T)$ may be computed from a continuum of European out-of-the-money (OTM) options. In particular

$$
K(t, T)=\frac{2}{B(t, T)(T-t)}\left(\int_{0}^{F\left(t, T_{1}\right)} \frac{\mathcal{P}\left(t, T, T_{1}, X\right)}{X^{2}} d X+\int_{F\left(t, T_{1}\right)}^{\infty} \frac{\mathcal{C}\left(t, T, T_{1}, X\right)}{X^{2}} d X\right),
$$

where $B(t, T)$ is the time- $t$ price of a zero-coupon bond maturing at time $T$, and $\mathcal{P}\left(t, T, T_{1}, X\right)$ and $\mathcal{C}\left(t, T, T_{1}, X\right)$ denote the time- $t$ price of a European put and call option, respectively, expiring at time $T$ with strike $X$ on a futures contract expiring at time $T_{1}$. This relation is exact when the futures price process is continuous (see e.g. Carr and Madan (1998), Demeterfi, Derman, Kamal, and Zou (1999) and Britten-Jones and Neuberger (2000)) and holds up to a small approximation error, when the futures price process exhibits jumps (see e.g. Jiang and Tian (2005) and Carr and Wu (2009)). For completeness, in the Appendix, we derive (3) in the case where $F\left(t, T_{1}\right)$ follows a jump-diffusion process. ${ }^{6}$ 
In practice, $V(t, T)$ is the realized annualized discretely (rather than continuously) sampled futures return variance. In a typical variance swap contract, the asset price is sampled each business day at the official close or settlement and variance is computed in terms of log returns assuming the mean of daily returns is zero. ${ }^{7}$ For a variance swap with $N$ business days to expiry, we define a set of dates $t=t_{0}<t_{1}<\ldots<t_{N}=T$ with $\Delta t=t_{i}-t_{i-1}=1 / 252 . V(t, T)$ is then computed as

$$
V(t, T)=\frac{1}{N \Delta t} \sum_{i=1}^{N} R\left(t_{i}\right)^{2},
$$

where $R\left(t_{i}\right)=\log \left(F\left(t_{i}, T_{1}\right) / F\left(t_{i-1}, T_{1}\right)\right)$.

Now, for each business day in the sample, we compute the synthetic variance swap rate, $K(t, T)$, using (3), and the realized futures return variance over the life of the swap, $V(t, T)$, using (4). We then compute two performance measures of a long position in a variance swap contract with a notional amount of $L=100$ USD held to expiration. The first is simply the dollar payoff given by

$$
(V(t, T)-K(t, T)) 100
$$

while the second is the continuously compounded excess return (since $K(t, T)$ can be regarded as the forward cost of a variance swap contract) given by

$$
\log (V(t, T) / K(t, T))
$$

These are the same two measures considered by Carr and Wu (2009), making our results directly comparable to theirs. The sample mean of (5) is an estimate of the average variance risk premium in dollar terms, while the sample mean of (6) is an estimate of the average variance risk premium in log return terms.

\section{Data}

Prices of crude oil and natural gas futures and options were obtained from NYMEX (the New York Mercantile Exchange). ${ }^{8}$ We use daily data on settlement prices from January 2, 1996 until November 30, 2006 - a total of 2750 business days. ${ }^{9}$ For both commodities, NYMEX lists futures contracts with monthly expirations several years into the future. It also lists American-style options on these futures, expiring slightly before the underlying contracts. ${ }^{10}$ On each business day, we select the futures contract with the shortest maturity among those 
futures contracts for which the options have more than 10 business days to expiration. We then select all OTM put and call options on this futures contract that have open interest in excess on 100 contracts, and have prices larger than 0.05 USD in the case of crude oil options and 0.005 USD in the case of natural gas options. The reason for requiring option prices to exceed the given thresholds is that crude oil options are quoted with a precision of 0.01 USD, and natural gas options are quoted with a precision of 0.001 USD. Generally, a large number of options meet these selection criteria. The average number of options is 25 for crude oil and 41 for natural gas, while the maximum number of options is 73 for crude oil and 122 for natural gas. For the interest rate, we use the three month LIBOR rate obtained from DataStream.

Since the options are American-style while the synthetic variance swap formula utilizes European-style options, it is necessary to convert the American option prices into European option prices by subtracting an estimate of the early exercise premium. ${ }^{11}$ This is done using the same approach as in Trolle and Schwartz (2009) (see also Broadie, Chernov, and Johannes (2007)). ${ }^{12}$ The estimated early exercise premium is always very small since we only use shortmaturity, OTM options.

Suppose at time $t$ we have a range of options expiring at time $T$ on a futures contract maturing at time $T_{1}$, and let $\sigma$ denote the Black (1976a) implied volatility of the option that is closest to at the money (ATM). In a Black (1976a) log-normal setting, for an option with strike $X$, moneyness defined as

$$
d=\frac{\log \left(X / F\left(t, T_{1}\right)\right)}{\sigma \sqrt{(T-t)}}
$$

approximately gives the number of standard deviations that the log strike is away from the log futures price. We truncate the first integral in (3) at $X_{\min }=F\left(t, T_{1}\right) e^{-10 \sigma \sqrt{(T-t)}}$, corresponding to $d=-10$, and the second integral in (3) at $X_{\max }=F\left(t, T_{1}\right) e^{10 \sigma \sqrt{(T-t)}}$, corresponding to $d=10$. The integrals are evaluated with "Simpson's rule" using 999 integration points for each integral. On a given day, options prices corresponding to the required strikes in the integration rule are obtained by first linearly interpolating between the available Black (1976a) implied volatilities and then converting from implied volatilities to prices. For strikes below the lowest available strike, we use the implied volatility at the lowest strike. Similarly, for strikes above the highest available strike, we use the implied volatility at the highest strike. This is basically the same interpolation/extrapolation approach as that used by Carr and Wu (2009). The approximation error caused by the extrapolation of implied volatilities is small, since option prices are very low in the regions of strikes where extrapolation is necessary, see 
Jiang and Tian (2005) for an extensive discussion. Exhibit 1 shows the implied volatility smiles on November 1st, 2006 and illustrates the interpolation/extrapolation scheme.

A synthetic 30 calendar day variance swap rate for the S\&P 500 index (SPX) is easily obtained by squaring the CBOE volatility index (VIX). This is because the VIX squared approximates the conditional risk-neutral expectation of the realized 30 calendar day S\&P 500 index variance. It is constructed along the lines of (3), using OTM S\&P 500 index options along with a particular discretization scheme as well as interpolation between two option maturities to obtain a constant 30 calendar day maturity. ${ }^{13}$ Daily data on the VIX and SPX indices was downloaded from the CBOE website.

\section{Results}

\subsection{Properties of variance swap rates and realized variances}

Exhibit 2 shows summary statistics of the variance swap rates and realized variances. For all three assets, the mean variance swap rate is larger than the mean realized variance, reflecting a negative variance risk premium in dollar terms on average. Natural gas is the most volatile of the three markets. Not only is the variance of futures prices the largest on average, but the volatility of the variance is also the largest. This holds true for both the variance swap rate and realized variance. In fact, natural gas is the most volatile of all major commodity markets except for electricity. Of the three markets analyzed, crude oil is the second most volatile, while the S\&P 500 index is the least volatile. In all three markets, the variance swap rate and realized variance display positive skewness and excess kurtosis. ${ }^{14}$

Exhibits $3-5$ show the time-series of the variance swap rate and realized variance in the three markets. Volatility in the crude oil market is very sensitive to geopolitical events with the variance swap rate peaking after the September 11, 2001 terrorist attacks and in the run-up to the US-led invasion of Iraq on March 20, 2003. Volatility in the natural gas market displays a high degree of seasonality, with volatility typically peaking during the winter months when demand for natural gas for heating purposes peaks. Since both supply and demand is fairly price inelastic, higher-than-expected demand during the winter due to exceptionally cold weather typically cause spikes in natural gas prices. ${ }^{15}$ The natural gas market is also exposed to disruptions in supply. For instance, volatility rose sharply around Hurricane Katrina which affected gas production in the Gulf of Mexico. For the S\&P 500 index, the variance swap rate 
peaks around the time LTCM disintegrated, after the September 11, 2001 terrorist attacks, and after WorldCom filed for Chapter 11 bankruptcy protection.

Exhibit 6 displays the correlations between daily changes in variance swap rates, daily changes in the estimated variances of the underlying contracts based on an $\operatorname{EGARCH}(1,1)$ specification, and daily log returns of the underlying futures contracts. First, while changes in the crude oil and natural gas variance swap rates display a small positive correlation (0.08), both are virtually uncorrelated with changes in the variance swap rate for S\&P 500 equity index. Second, for crude oil, the correlation between futures returns and changes in variance is negative but small (the correlation with changes in the variance swap rate is -0.04 , and the correlation with changes in the GARCH variance is -0.14). This is consistent with results reported in Trolle and Schwartz (2009) who argue that crude oil volatility is largely unspanned

by the futures contracts. ${ }^{16}$ For natural gas, the correlation between futures returns and changes in variance is moderately positive (the correlation with changes in the variance swap rate and the GARCH variance is 0.36 and 0.43 , respectively), suggesting that a larger component of natural gas volatility is spanned by the futures contracts than is the case for crude oil. In contrast, it is well-known that for the S\&P500 index, the correlation between index returns and changes in variance is highly negative (in our sample, the correlation with changes in the variance swap rate and the GARCH variance is -0.77 and -0.80 , respectively). ${ }^{17}$

\subsection{Variance risk premia}

We consider a long position in a variance swap with a notional of 100 USD. Exhibit 7 shows summary statistics of the dollar payoff, $V(t, T)-K(t, T)$, and log excess return, $\log (V(t, T) / K(t, T))$, for both energy commodities as well as the S\&P 500 index. The $T$-statistics are adjusted for the autocorrelation induced by the overlap in observations. The mean payoff and log excess return is negative for all three assets. The mean payoff is most negative for natural gas (-3.58 USD), followed by crude oil (-2.96 USD) and the S\&P 500 index (-1.62 USD). The mean log excess return is most negative for the S\&P 500 index (-56.9 percent) followed by crude oil (-26.5 percent) and natural gas (-22.3 percent). The reason why the ranking between the three assets changes, when considering returns instead of payoffs, is that the level of variance is very different between the three assets. The mean payoffs and excess returns are statistically significant in all three markets, with the $T$-statistics largest for S\&P 500 index followed by crude oil and natural gas. 
The distributions of payoffs exhibit fat tails for all three assets. It is fairly symmetric for crude oil as well as the S\&P 500 index but displays positive skewness for natural gas. In contrast, the distributions of log excess returns are closer to normal although they do exhibit positive skewness and excess kurtosis.

Finally, the table also reports the annualized Sharpe ratios (computed from standard deviations adjusted for the autocorrelation induced by the overlap in observations) of shorting variance swaps. These are highest for the S\&P 500 index (1.02) followed by crude oil (0.59) and natural gas (0.35). ${ }^{18}$ To put these numbers into perspective, Duarte, Longstaff, and Yu (2007) report annualized Sharpe ratios between 0.47 and 0.82 from shorting interest rate (specifically cap) volatility, and Carr and Wu (2009) report annualized Sharpe ratios between 0 and 0.55 from shorting variance on selected individual stocks. Hence, although a strategy of shorting variance in the two energy markets is not quite as attractive as shorting S\&P 500 index variance, its performance seems comparable to a strategy of shorting interest rate volatility or variance on individual stocks.

Exhibit 8 displays the three time series of log excess returns, and Exhibit 9 shows the empirical density functions of log excess returns as well as the normal distributions having the same means and the same variances as those estimated from the samples.

\subsection{Seasonality in the natural gas variance risk premium}

As mentioned above, natural gas volatility exhibits strong seasonality with volatility peaking during the cold months. For instance, the mean variance swap rate during October to March is 44.3 percent compared with 28.6 percent during April to September. An interesting question is whether the variance risk premium also exhibits seasonality. To this end, we compare the performance of variance swaps initiated during October to March (the cold season) with variance swaps initiated during April to September (the warm season). Exhibit 10 shows summary statistics of the payoff, $V(t, T)-K(t, T)$, and $\log$ excess return, $\log (V(t, T) / K(t, T))$. The mean payoff is more negative during the cold season than during the warm season (-3.77 USD vs. -3.40 USD) and so is the mean log excess return (-24.5 percent vs. -20.2 percent). ${ }^{19}$ Also, the annualized Sharpe ratio of shorting natural gas variance swaps is higher during the cold season than during the warm season (0.38 vs. 0.35). However, the difference between the mean payoffs and the difference between the mean log excess returns during the cold and the warm season is not statistically significant. ${ }^{20}$ 


\subsection{Time-variation in variance risk premia}

As in Carr and Wu (2009) we test for time-variation in the variance risk premia by running the following two regressions:

$$
V(t, T)=a+b K(t, T)+\epsilon
$$

and

$$
\log V(t, T)=a+b \log K(t, T)+\epsilon .
$$

Under the null hypothesis of constant variance risk premia in dollar terms, the slope in (8) is one. Absence of variance risk premia in dollar terms would further imply that the intercept in (8) is zero. Similarly, under the null hypothesis of constant variance risk premia in log return terms, the slope in (9) is one. Zero variance risk premia in log return terms would further imply that the intercept in (9) is zero.

Exhibit 11 displays estimates of both regressions. The regressions are estimated by OLS with the $T$-statistics under the null hypotheses of $a=0$ and $b=1$ adjusted for the autocorrelation induced by the overlap in observations. For both energy commodities, the slope estimates in (8) are significantly less than one and are of similar magnitude. This indicates that energy variance risk premia in dollar terms are time-varying and negatively correlated with the level of the variance swap rate; i.e. variance risk premia in dollar terms tend to become more negative when the variance swap rate increases. ${ }^{21}$ In contrast, the slope estimates in (9) are closer to one and only significantly different from one in the case of crude oil. This shows that energy variance risk premia in log return terms, particularly in the case of natural gas, are more constant over time and not highly correlated with the log variance swap rate. The results for the S\&P 500 index are very similar.

\subsection{Fundamentals and variance risk premia}

In this section, we first investigate the extent to which energy variance risk premia can be explained within a standard asset pricing framework; in particular, whether the variance risk premia reflect compensation for exposure to equity and commodity market risks. We regress the log excess returns on variance swaps, $r_{t, T}^{V S}$, on the contemporaneous log excess returns on the S\&P 500 index, $r_{t, T}^{S P X}$, and the log excess returns on the S\&P Goldman Sachs Commodity Index ${ }^{22}, r_{t, T}^{S P G S C I}$

$$
r_{t, T}^{V S}=\alpha+\beta^{S P X} r_{t, T}^{S P X}+\beta^{S P G S C I} r_{t, T}^{S P G S C I}+\epsilon .
$$


Exhibit 12 shows that both energy variance swaps have an insignificant loading on the equity market portfolio. However, both variance swaps load significantly on the commodity market portfolio - crude oil with a negative sign and natural gas with a positive sign - but the $R^{2} \mathrm{~s}$ are small and the alphas are significant and close to the unconditional means of log excess returns reported in Exhibit 7. Hence, standard asset pricing models do not seem to be able to explain energy variance risk premia. ${ }^{23}$ In the case of crude oil, this is consistent with the finding in Trolle and Schwartz (2009) that variance risk is largely orthogonal to the underlying futures market. The results are also consistent with studies that show the failure of standard asset pricing models in accounting for risk premia in commodity futures; see, e.g. Jagannathan (1985) for one such study.

Next, we investigate if commodity specific factors may drive energy variance risk premia. In particular, we consider inventories which have been shown to forecast excess returns on commodity futures; see, e.g., Dincerler, Khokher, and Simin (2006) and Gorton, Hayashi, and Rouwenhorst (2008) who find that futures risk premia tend to be larger when inventories are low. ${ }^{24}$ We use weekly inventory data from the Energy Information Administration (EIA). For crude oil we use the item "Crude Oil (Excluding SPR)" and for natural gas we use the item "Working Gas in Underground Storage, Total Lower 48 States". To control for seasonality in inventories, we use relative inventories, which we define as the log of the ratio between the level of inventories in a given week and the average level of inventories for that week over the past five years. We regress the log excess returns on variance swaps from $t$ to $T, r_{t, T}^{V S}$, on the relative inventory level at $t^{25}$

$$
r_{t, T}^{V S}=a+b \text { inventory }_{t}+\epsilon
$$

Exhibit 13 shows that $b$ has a positive sign in both regressions, implying that variance risk premia tend to be more negative when relative inventories are low - similar to the findings for futures risk premia. However, only in the case of crude oil is $b$ significant and, even then, the $R^{2}$ is relatively low. ${ }^{26}$ Therefore, it seems that both systematic and commodity specific factors have a difficult time accounting for energy variance risk premia.

\subsection{Option-like return profile of variance swaps}

Exhibit 14 reports results from regressing the log excess return on a variance swap on the annualized log return on the underlying asset over the life of the swap. In the crude oil regression the relationship is negative but insignificant, while in the natural gas regression 
there is a statistically significant positive relationship. In the S\&P 500 regression there is a statistically very significant negative relationship. This is consistent with the results in Section 4.1, that the correlation between daily underlying returns and changes in the GARCH variance is negative but small for crude oil, moderately positive for natural gas and highly negative for the S\&P 500 index.

Studies on equity volatility have found that the negative correlation between index volatility and index returns is mainly (or only) due to a negative correlation when index returns are negative (see, e.g., Figlewski and Wang (2000)). This suggests that the relationship between variance swap returns and returns of the underlying asset is non-linear in case of the S\&P 500 index. Possibly, the relationship is also non-linear for the two energy commodities. To see if this is the case, Exhibit 14 also reports results from running the regressions, first using only those observations where the return on the underlying asset is negative, and then using only those observations where the return on the underlying asset is positive. For natural gas and the S\&P 500 index, we find a strongly non-linear relationship. For natural gas, there is a statistically highly significant positive relationship between variance swap returns and futures returns, when the futures returns are positive, but a much weaker (negative) relationship when the futures returns are negative. In contrast, for the S\&P 500 index, there is a statistically highly significant negative relationship between variance swap returns and the index returns, when the index returns are negative, but an insignificant relationship when the index returns are positive. For crude oil, the relationship is weaker although there is a statistically significant negative relationship between variance swap returns and futures returns, when the futures returns are negative, but virtually no relationship when the futures returns are positive.

Hence, the return profile of a natural gas variance swap resembles that of a call option, while the return profile of an S\&P 500 index variance swap resembles the return profile of a put option. The return profile of a crude oil variance swap has a less distinctive pattern, although if anything it also resembles the return profile of a put option. This is also evident from Exhibit 15, which shows scatter-plots of log excess variance swap returns vs. annualized contemporaneous log returns of the underlying assets.

\section{Conclusion}

This paper has investigated variance risk premia in energy commodities, particularly crude oil and natural gas, using a robust model-independent approach. The analysis is based on 11 
years of daily data on futures and options trading on NYMEX.

We find that the average variance risk premia are negative for both energy commodities, but more strongly statistically significant for crude oil than for natural gas. In the case of natural gas, we find some degree of seasonality in the risk premium, although it is not statistically significant. Furthermore, energy variance risk premia in dollar terms are timevarying and correlated with the level of the variance swap rate, while energy variance risk premia in return terms, particularly in the case of natural gas, are much less correlated with the $(\log )$ variance swap rate. Moreover, it is difficult to explain the level and variation in energy variance risk premia with systematic factors (returns on equity and commodity market portfolios) or commodity specific factors (inventories). Finally, the return profile of a natural gas variance swap resembles that of a call option, while the return profile of a crude oil variance swap has a less distinctive pattern, although if anything it resembles the return profile of a put option.

During our sample period, the annualized Sharpe ratios from shorting variance is 0.59 for crude oil and 0.35 for natural gas. This is not nearly as high as the annualized Sharpe ratio of shorting S\&P 500 index variance, but is comparable to the annualized Sharpe ratios, reported in other studies, of shorting interest rate volatility or variance on individual stocks.

In future work we plan to explore the economic underpinnings of the negative energy variance risk premia and their dynamics. It will also be interesting to investigate how energy variance swaps fit into diversified commodity portfolios.

\section{Appendix}

Assume that the risk-neutral dynamics of the futures price $F\left(t, T_{1}\right)$ is given by the following jump-diffusion process:

$$
\frac{d F\left(t, T_{1}\right)}{F\left(t, T_{1}\right)}=\sqrt{v(t)} d W(t)+\left(e^{x}-1\right) d N(t)-\int_{\mathbb{R}}\left(e^{x}-1\right) f(x) d x \lambda(t) d t,
$$

where $W(t)$ is a Wiener process, $v(t)$ is the instantaneous variance of the diffusion component, $N(t)$ is a Poisson process with time-varying intensity $\lambda(t), x$ is the jump size conditional on a jump occurring, and $f(x)$ is the density of the jump-size distribution. By Itô's lemma

$$
d \log F\left(t, T_{1}\right)=-\frac{1}{2} v(t) d t+\sqrt{v(t)} d W(t)+x d N(t)-\int_{\mathbb{R}}\left(e^{x}-1\right) f(x) d x \lambda(t) d t,
$$


so that

$\log F\left(T, T_{1}\right)=\log F\left(t, T_{1}\right)-\frac{1}{2} \int_{t}^{T} v(s) d s+\int_{t}^{T} \sqrt{v(s)} d W(s)+\sum_{i=1}^{N(T)} x-\int_{\mathbb{R}}\left(e^{x}-1\right) f(x) d x \int_{t}^{T} \lambda(s) d s$.

The annualized realized quadratic variation of futures returns over the period $[t, T], T \leq T_{1}$, is given by

$$
V(t, T)=\frac{1}{T-t}\left(\int_{t}^{T} v(s) d s+\sum_{i=1}^{N(T)} x^{2}\right) .
$$

Combining (14) and (15) and taking expectations, we obtain

$E_{t}^{Q}[V(t, T)]=-\frac{2}{T-t} E_{t}^{Q}\left[\log \left(\frac{F\left(T, T_{1}\right)}{F\left(t, T_{1}\right)}\right)\right]-\frac{2}{T-t} \int_{\mathbb{R}}\left(e^{x}-1-x-\frac{1}{2} x^{2}\right) f(x) d x \int_{t}^{T} \lambda(s) d s(16)$

From Carr and Madan (2001) it follows that for any fixed $Z$ we can write any twice continuously differentiable function $g$ of $F\left(T, T_{1}\right)$ as

$$
\begin{aligned}
g\left(F\left(T, T_{1}\right)\right)= & g(Z)+g^{\prime}(Z)\left(F\left(T, T_{1}\right)-Z\right)+\int_{0}^{Z} g^{\prime \prime}(X)\left(X-F\left(T, T_{1}\right)\right)^{+} d X \\
& +\int_{Z}^{\infty} g^{\prime \prime}(X)\left(F\left(T, T_{1}\right)-X\right)^{+} d X .
\end{aligned}
$$

In particular, with $g(F)=\log F$ and $Z=F\left(t, T_{1}\right)$, taking expectations, and rearranging, we obtain

$E_{t}^{Q}\left[\log \left(\frac{F\left(T, T_{1}\right)}{F\left(t, T_{1}\right)}\right)\right]=-\frac{1}{B(t, T)}\left(\int_{0}^{F\left(t, T_{1}\right)} \frac{\mathcal{P}\left(t, T, T_{1}, X\right)}{X^{2}} d X+\int_{F\left(t, T_{1}\right)}^{\infty} \frac{\mathcal{C}\left(t, T, T_{1}, X\right)}{X^{2}} d X\right)$

Inserting this expression in (16) and ignoring the jump-induced term, which Gatheral (2006) and Carr and $\mathrm{Wu}(2009)$ argue is very small for plausible parameters, gives (3). 
Panel A: CL

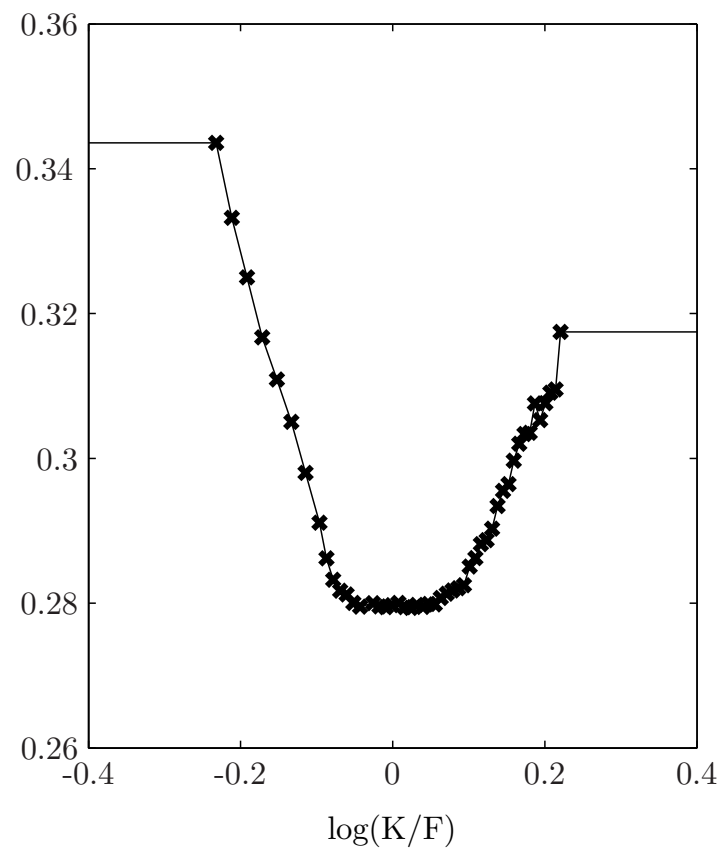

Panel B: NG

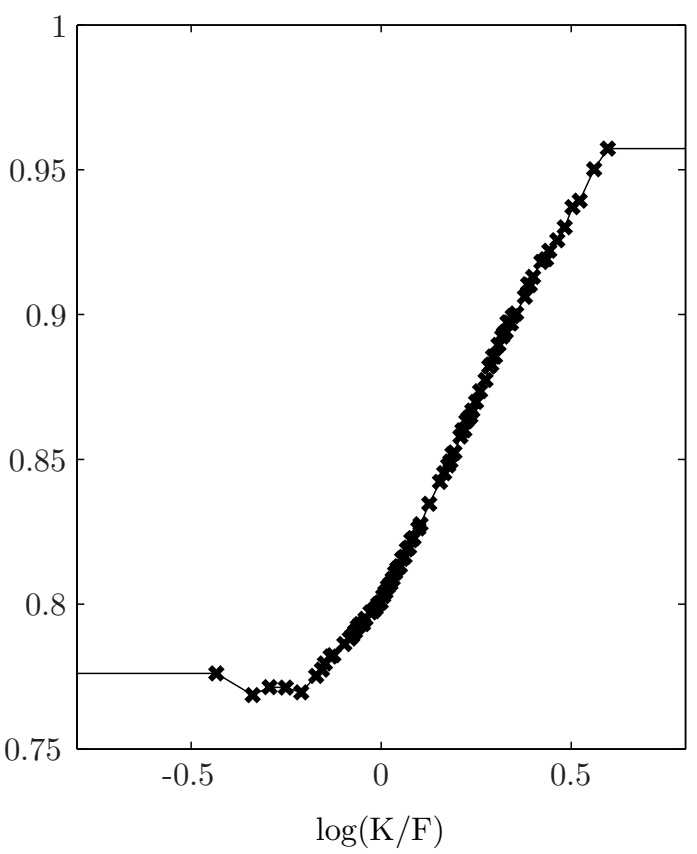

Exhibit 1: Implied volatility smiles on November 1st, 2006

Notes: Implied volatility smiles for crude oil (Panel A) and natural gas (Panel B). To obtain implied volatilities (and thereby option prices) corresponding to the required strikes in the integration rule, we use linear interpolation and flat extrapolation. 


\begin{tabular}{|c|c|c|c|c|c|c|}
\hline & \multicolumn{2}{|c|}{ CL } & \multicolumn{2}{|c|}{$\mathrm{NG}$} & \multicolumn{2}{|c|}{ SPX } \\
\hline & $K(t, T)$ & $V(t, T)$ & $K(t, T)$ & $V(t, T)$ & $K(t, T)$ & $V(t, T)$ \\
\hline Mean & 0.151 & 0.122 & 0.363 & 0.328 & 0.048 & 0.031 \\
\hline Median & 0.135 & 0.103 & 0.323 & 0.265 & 0.041 & 0.022 \\
\hline Minimum & 0.041 & 0.015 & 0.083 & 0.027 & 0.010 & 0.004 \\
\hline Maximum & 0.618 & 0.526 & 2.447 & 2.674 & 0.209 & 0.205 \\
\hline Std. dev. & 0.073 & 0.070 & 0.221 & 0.272 & 0.031 & 0.031 \\
\hline Skewness & 2.234 & 1.943 & 2.363 & 2.699 & 1.631 & 2.486 \\
\hline Kurtosis & 9.886 & 8.111 & 13.653 & 14.356 & 6.492 & 10.490 \\
\hline Number of obs. & 2702 & 2750 & 2678 & 2750 & 2748 & 2750 \\
\hline
\end{tabular}

Exhibit 2: Summary statistics of $K(t, T)$ and $V(t, T)$

Notes: Summary statistics of the variance swap rates, $K(t, T)$, and realized variances, $V(t, T)$. $C L$ denotes crude oil, $N G$ denotes natural gas, and $S P X$ denotes the S\&P 500 equity index. 


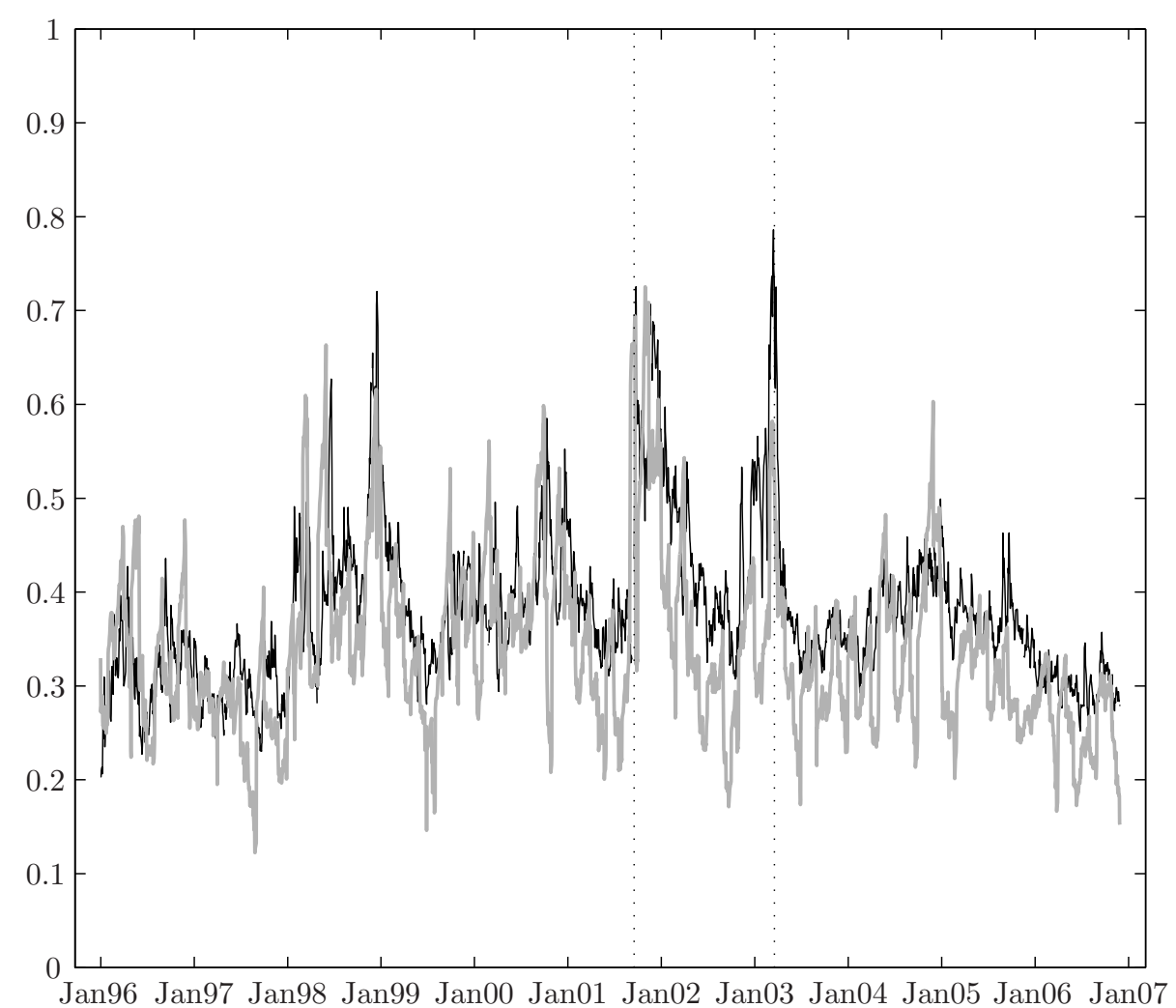

Exhibit 3: Time series of $\sqrt{K(t, T)}$ and $\sqrt{V(t, T)}$ for crude oil Notes: $\_$denotes $\sqrt{K(t, T)}$ and denotes $\sqrt{V(t, T)}$. The vertical dotted lines mark the September 11, 2001 terrorist attacks, and the US-led invasion of Iraq on March 20, 2003, respectively. 


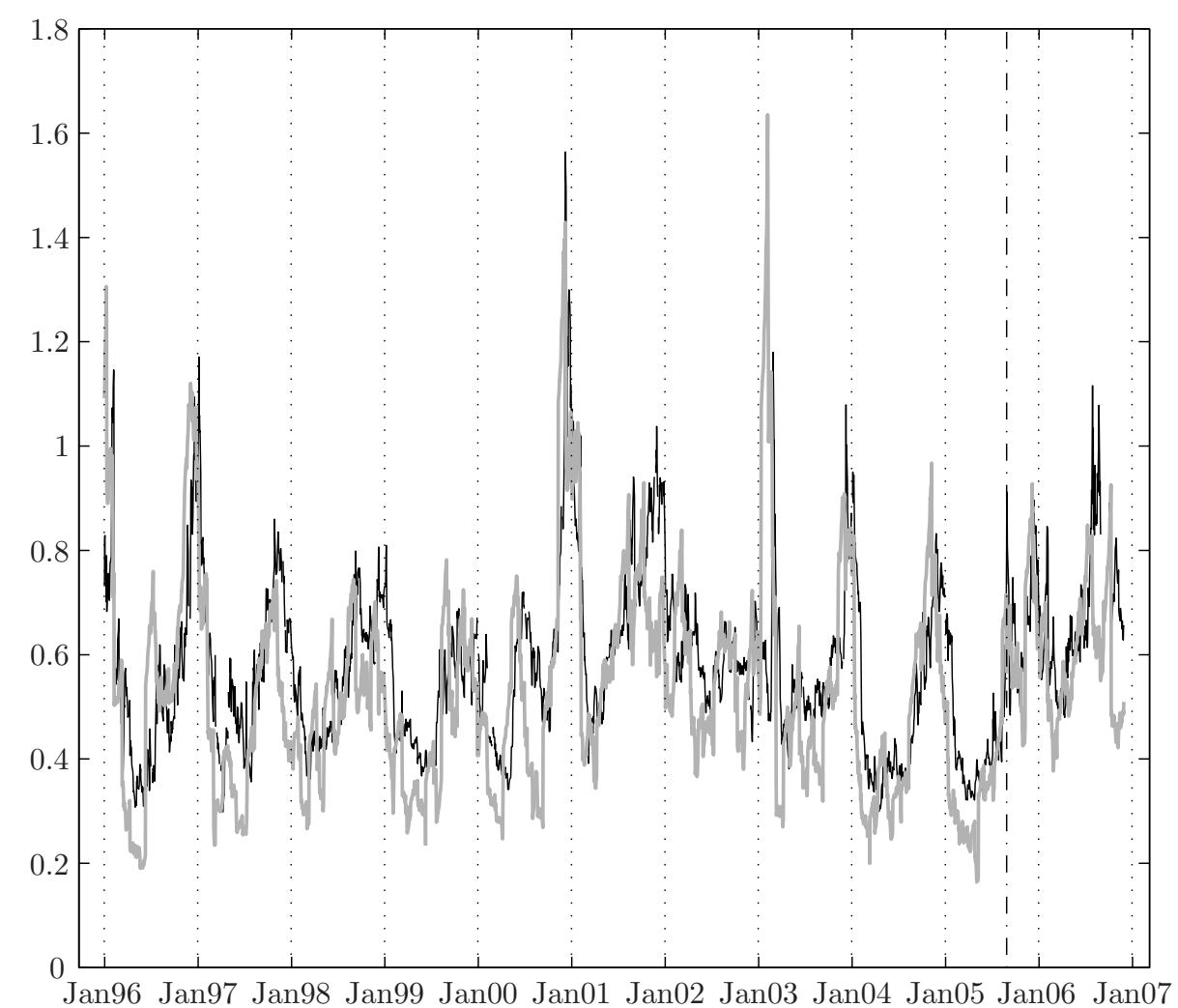

Exhibit 4: Time series of $\sqrt{K(t, T)}$ and $\sqrt{V(t, T)}$ for natural gas Notes: — denotes $\sqrt{K(t, T)}$ and denotes $\sqrt{V(t, T)}$. The vertical dotted lines mark January 1st of each year and the vertical dash-dotted line marks August 29, 2005, when Hurricane Katrina hit New Orleans. 


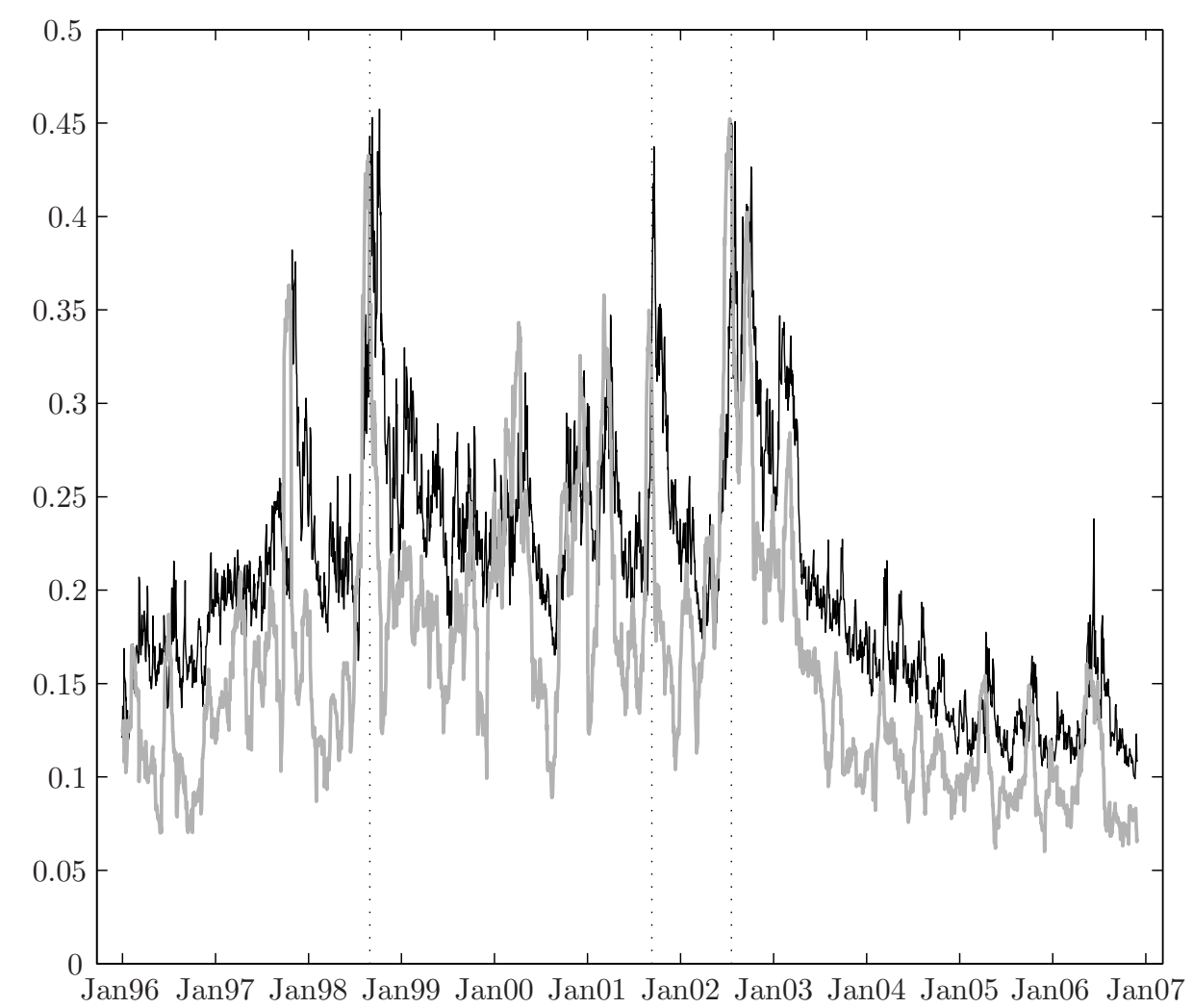

Exhibit 5: Time series of $\sqrt{K(t, T)}$ and $\sqrt{V(t, T)}$ for the S\&P 500 equity index Notes: - denotes $\sqrt{K(t, T)}$ and denotes $\sqrt{V(t, T)}$. The vertical dotted lines mark the LTCM crisis starting around August 31, 1998, the September 11, 2001 terrorist attacks, and WorldCom filing for Chapter 11 bankruptcy protection on July 21, 2002, respectively. 


\begin{tabular}{lccccccccc}
\hline & $\Delta K_{C L}$ & $\Delta K_{N G}$ & $\Delta K_{S P X}$ & $\Delta \sigma_{C L}^{2}$ & $\Delta \sigma_{N G}^{2}$ & $\Delta \sigma_{S P X}^{2}$ & $R_{C L}$ & $R_{N G}$ & $R_{S P X}$ \\
\hline$\Delta K_{C L}$ & 1.000 & & & & & & & & \\
$\Delta K_{N G}$ & 0.079 & 1.000 & & & & & & & \\
$\Delta K_{S P X}$ & 0.003 & -0.018 & 1.000 & & & & & & \\
$\Delta \sigma_{C L}^{2}$ & 0.337 & 0.031 & -0.021 & 1.000 & & & & & \\
$\Delta \sigma_{N G}^{2}$ & 0.013 & 0.409 & 0.027 & 0.060 & 1.000 & & & & \\
$\Delta \sigma_{S P X}^{2}$ & 0.003 & 0.024 & 0.715 & 0.000 & 0.027 & 1.000 & & & \\
$R_{C L}$ & -0.035 & 0.079 & -0.004 & -0.144 & 0.139 & -0.013 & 1.000 & & \\
$R_{N G}$ & 0.006 & 0.358 & -0.014 & -0.014 & 0.425 & 0.025 & 0.310 & 1.000 & \\
$R_{S P X}$ & -0.022 & -0.008 & -0.766 & 0.027 & -0.008 & -0.799 & -0.022 & -0.021 & 1.000 \\
\hline
\end{tabular}

Exhibit 6: Correlations

Notes: Correlations between daily changes in variance swap rates $(\Delta K)$, daily changes in the estimated variances of the underlying assets based on an $\operatorname{EGARCH}(1,1)$ specification $\left(\Delta \sigma^{2}\right)$, and daily log returns of the underlying assets $(R)$. $C L$ denotes crude oil, $N G$ denotes natural gas, and $S P X$ denotes the S\&P 500 equity index. 


\begin{tabular}{lccccccc}
\hline & \multicolumn{3}{c}{$V(t, T)-K(t, T)$} & & \multicolumn{3}{c}{$\log (V(t, T) / K(t, T))$} \\
\cline { 2 - 3 } \cline { 7 - 8 } & CL & NG & SPX & & CL & NG & SPX \\
\hline Mean & -2.962 & -3.580 & -1.618 & & -0.265 & -0.223 & -0.569 \\
Medtatistics & -6.568 & -2.106 & -8.754 & & -8.689 & -5.197 & -15.367 \\
Minimum & -3.108 & -5.396 & -1.536 & & -0.273 & -0.219 & -0.591 \\
Maximum & -41.618 & -119.708 & -16.411 & & -1.663 & -1.874 & -2.043 \\
Standard deviation & 33.362 & 237.943 & 11.134 & & 1.410 & 2.206 & 1.175 \\
Skewness & 6.720 & 23.562 & 2.582 & & 0.437 & 0.549 & 0.504 \\
Kurtosis & 0.214 & 2.421 & 0.158 & & 0.129 & 0.299 & 0.393 \\
Number of obs. & 7.733 & 20.016 & 8.792 & & 3.613 & 3.572 & 3.289 \\
Sharpe ratio & 2702 & 2678 & 2748 & & 2702 & 2678 & 2748 \\
\hline
\end{tabular}

Exhibit 7: Summary statistics of payoffs and excess returns of variance swaps

Notes: Summary statistics of $V(t, T)-K(t, T)$, the payoff on a variance swap, and $\log (V(t, T) / K(t, T))$, the log excess return on a variance swap. $C L$ denotes crude oil, $N G$ denotes natural gas, and $S P X$ denotes the S\&P 500 equity index. "Sharpe ratio" refers to the annualized Sharpe ratios of shorting variance swaps. T-statistics and Sharpe ratios are computed from standard deviations estimated with the approach of Newey and West (1987) using a lag-length equal to the maximum variance swap maturity over the sample (33 business days for CL, 33 business days for NG, and 22 business days for SPX). 
Panel A: CL

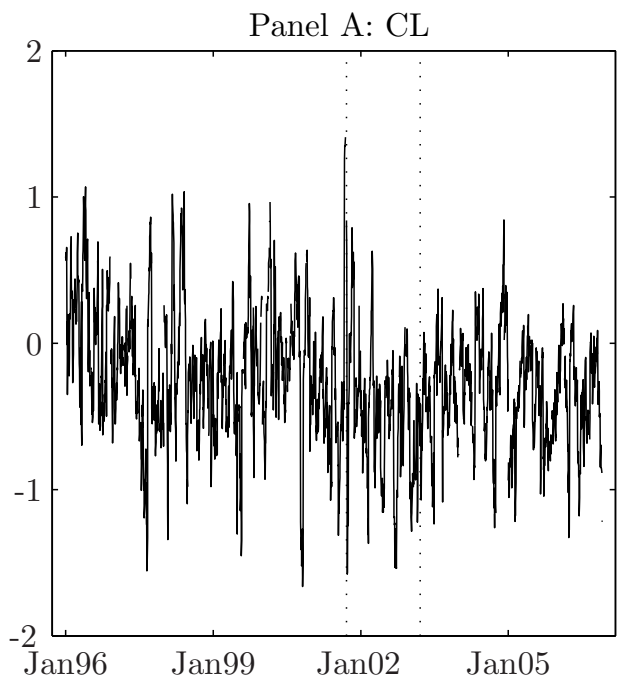

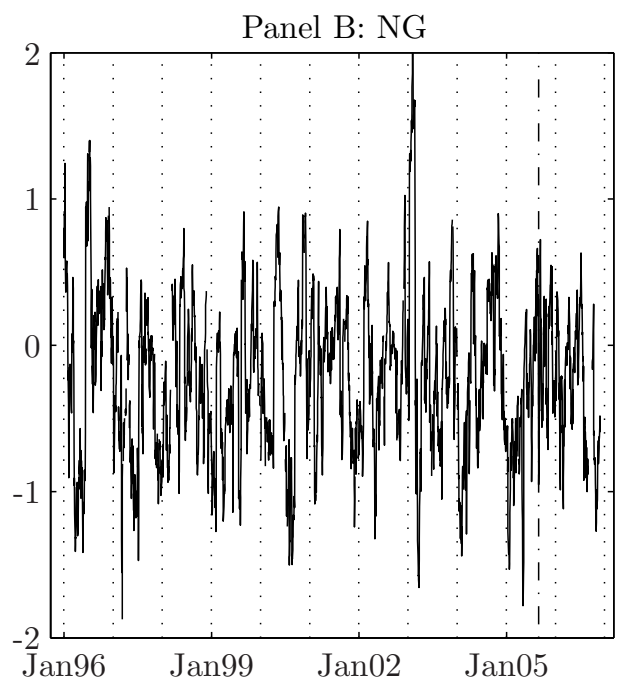

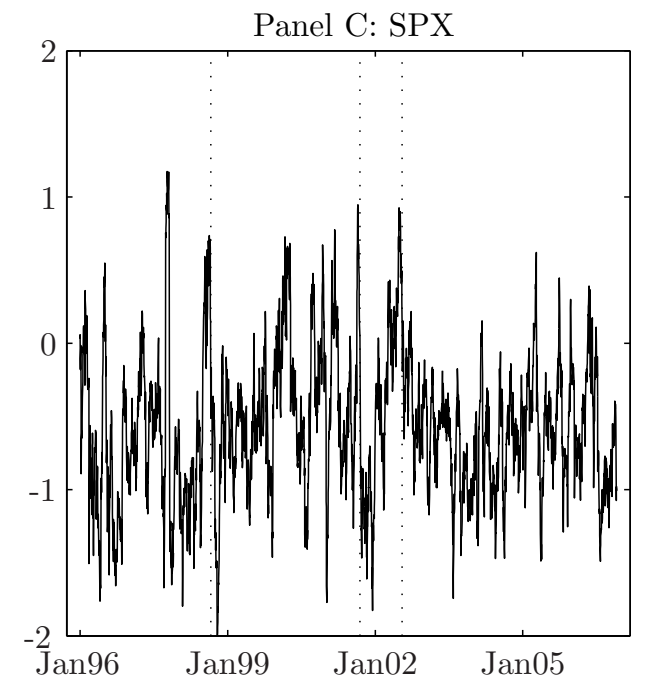

Exhibit 8: Time series of variance swap returns

Notes: Time series of $\log (V(t, T) / K(t, T))$, the log excess returns on a variance swap. $C L$ denotes crude oil, $N G$ denotes natural gas, and $S P X$ denotes the S\&P 500 equity index. For crude oil, the vertical dotted lines mark the September 11, 2001 terrorist attacks, and the US-led invasion of Iraq on March 20, 2003, respectively. For natural gas, the vertical dotted lines mark January 1st of each year and the vertical dash-dotted line marks August 29, 2005, when Hurricane Katrina hit New Orleans. For the S\&P 500 index, the vertical dotted lines mark the LTCM crisis starting around August 31, 1998, the September 11, 2001 terrorist attacks, and WorldCom filing for Chapter 11 bankruptcy protection on July 21, 2002, respectively. 

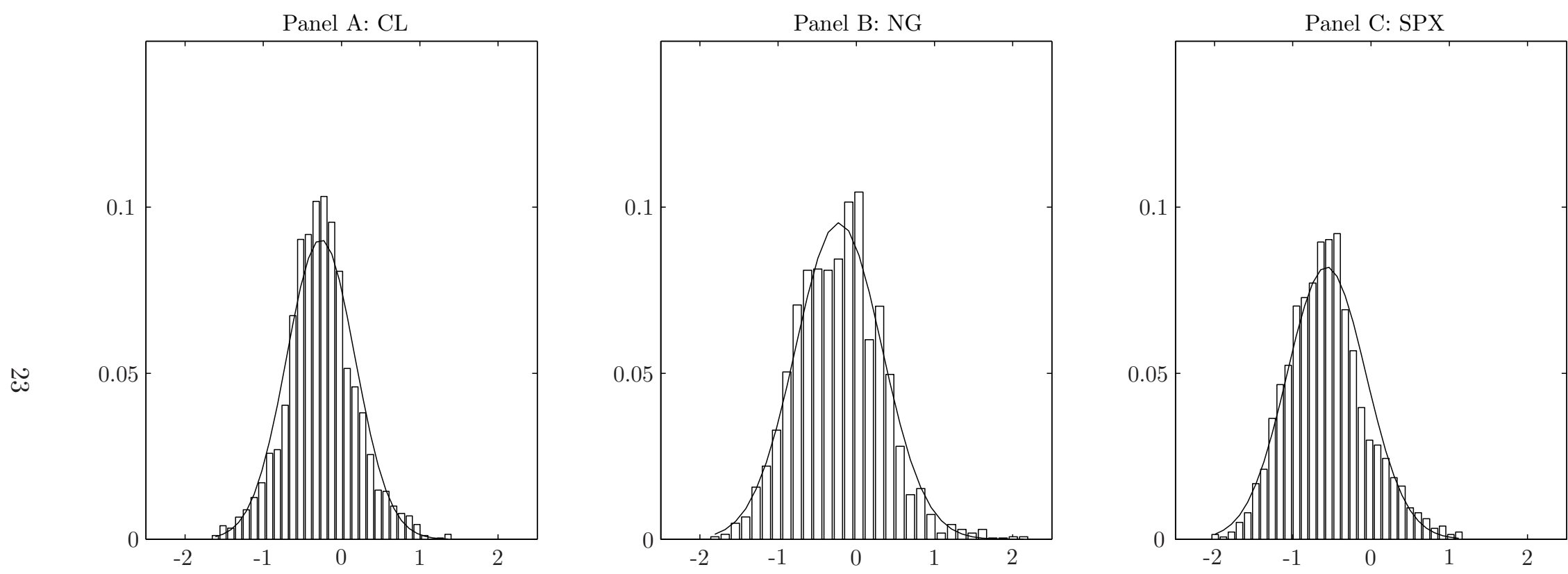

\section{Exhibit 9: Densities of variance swap returns}

Notes: The bars show the empirical density functions of the log excess returns on a variance swap. The curves show the normal distributions having the same means and the same variances as those estimated from the samples. $C L$ denotes crude oil, $N G$ denotes natural gas, and $S P X$ denotes the $\mathrm{S} \& \mathrm{P} 500$ equity index. 


\begin{tabular}{lccccc}
\hline & \multicolumn{2}{c}{$V(t, T)-K(t, T)$} & & \multicolumn{2}{c}{$\log (V(t, T) / K(t, T))$} \\
\cline { 2 - 3 } \cline { 5 - 6 } & Oct-Mar & Apr-Sep & & Oct-Mar & Apr-Sep \\
\hline Mean & -3.769 & -3.397 & & -0.245 & -0.202 \\
-statistics & -1.204 & -2.537 & & -3.923 & -3.686 \\
Median & -7.895 & -3.603 & & -0.286 & -0.140 \\
Minimum & -119.708 & -75.007 & & -1.874 & -1.780 \\
Maximum & 237.943 & 44.959 & & 2.206 & 1.400 \\
Standard deviation & 30.624 & 13.591 & & 0.577 & 0.520 \\
Skewness & 2.299 & -0.460 & & 0.630 & -0.113 \\
Kurtosis & 14.099 & 5.559 & & 4.076 & 2.892 \\
Number of obs. & 1318 & 1360 & & 1318 & 1360 \\
Sharpe ratio & - & - & & 0.377 & 0.349 \\
\hline
\end{tabular}

Exhibit 10: Seasonality in payoff and excess return on natural gas variance swap

Notes: Comparison of performance of natural gas variance swaps initiated during October to March with variance swaps initiated during April to September. The table shows summary statistics of $V(t, T)-K(t, T)$, the payoff on a variance swap, and $\log (V(t, T) / K(t, T))$, the $\log$ excess return on a variance swap. "Sharpe ratio" refers to the annualized Sharpe ratios of shorting variance swaps. T-statistics and Sharpe ratios are computed from standard deviations estimated with the approach of Newey and West (1987) using a lag-length equal to 33 business days - the maximum variance swap maturity over the sample. 


\begin{tabular}{|c|c|c|c|c|c|c|}
\hline & \multicolumn{3}{|c|}{$V(t, T)=a+b K(t, T)+\epsilon$} & \multicolumn{3}{|c|}{$\log V(t, T)=a+b \log K(t, T)+\epsilon$} \\
\hline & $a$ & $b$ & $R^{2}$ & $a$ & $b$ & $R^{2}$ \\
\hline CL & $\begin{array}{l}0.040 \\
(4.652)\end{array}$ & $\begin{array}{c}0.539 \\
(-7.870)\end{array}$ & 0.313 & $\begin{array}{l}-0.819 \\
(-6.078)\end{array}$ & $\begin{array}{c}0.720 \\
(-4.088)\end{array}$ & 0.322 \\
\hline NG & $\begin{array}{l}0.076 \\
(2.936)\end{array}$ & $\begin{array}{c}0.691 \\
(-4.589)\end{array}$ & 0.314 & $\begin{array}{l}-0.317 \\
(-3.734)\end{array}$ & $\begin{array}{c}0.919 \\
(-1.173)\end{array}$ & 0.450 \\
\hline SPX & $\begin{array}{l}0.001 \\
(0.271) \\
\end{array}$ & $\begin{array}{c}0.643 \\
(-4.203) \\
\end{array}$ & 0.428 & $\begin{array}{l}-0.506 \\
(-2.569) \\
\end{array}$ & $\begin{array}{l}1.019 \\
(0.339)\end{array}$ & 0.617 \\
\hline
\end{tabular}

Exhibit 11: Time-variation in variance risk premia

Notes: $K(t, T)$ is the variance swap rate, and $V(t, T)$ is the realized variance. $C L$ denotes crude oil, $N G$ denotes natural gas, and SPX denotes the S\&P 500 equity index. Regressions are estimated by OLS. The $T$-statistics under the null hypotheses of $a=0$ and $b=1$ are reported in parentheses. These are computed using the Newey and West (1987) estimator with a lag-length equal to the maximum variance swap maturity over the sample (33 business days for CL, 33 business days for NG, and 22 business days for SPX). 


\begin{tabular}{ccccc}
\hline & $\alpha$ & $\beta^{S P X}$ & $\beta^{S P G S C I}$ & $R^{2}$ \\
\hline CL & -0.264 & 0.036 & -0.069 & 0.017 \\
\multirow{3}{*}{ NG } & $(-8.389)$ & $(0.776)$ & $(-1.918)$ & 0.038 \\
\multirow{2}{*}{ SPX } & -0.223 & -0.043 & 0.134 & 0.194 \\
& $(-5.260)$ & $(-0.961)$ & $(3.194)$ & 0.002 \\
\hline
\end{tabular}

Exhibit 12: Variance risk premia and systematic factors

Notes: Estimates of the regressions

$$
r_{t, T}^{V S}=\alpha+\beta^{S P X} r_{t, T}^{S P X}+\beta^{S P G S C I} r_{t, T}^{S P G C I}+\epsilon,
$$

where $r_{t, T}^{V S}$ denotes the log excess return on a variance swap, $r_{t, T}^{S P X}$ denotes the log excess return on the S\&P 500 index, and $r_{t, T}^{S P G S C I}$ denotes the log excess returns on the S\&P Goldman Sachs Commodity Index. $C L$ denotes crude oil, $N G$ denotes natural gas, and $S P X$ denotes the S\&P 500 equity index. Regressions are estimated by OLS. The $T$-statistics under the null hypotheses of $\alpha=0$ and $\beta=0$ are reported in parentheses. These are computed using the Newey and West (1987) estimator with a lag-length equal to the maximum variance swap maturity over the sample (33 business days for CL, 33 business days for NG, and 22 business days for SPX). 


\begin{tabular}{lccc}
\hline & $a$ & $b$ & $R^{2}$ \\
\hline $\mathrm{CL}$ & -0.280 & 0.854 & 0.019 \\
& $(-9.626)$ & $(2.120)$ & \\
$\mathrm{NG}$ & -0.238 & 0.100 & 0.000 \\
\hline
\end{tabular}

Exhibit 13: Variance risk premia and inventories

Notes: Estimates of the regressions

$$
r_{t, T}^{V S}=a+b \text { inventor } y_{t}+\epsilon
$$

where $r_{t, T}^{V S}$ denotes the log excess return on a variance swap and inventory $y_{t}$ denotes the log of the ratio between the current level of inventories and the average level for that week taken over the previous five years. $C L$ denotes crude oil and $N G$ denotes natural gas. These regressions are based on weekly data. Regressions are estimated by OLS. The $T$-statistics under the null hypotheses of $a=0$ and $b=0$ are reported in parentheses. These are computed using the Newey and West (1987) estimator with a lag-length equal 7 which is the maximum overlap in observations. 


\begin{tabular}{|c|c|c|c|c|c|c|c|c|c|}
\hline & \multicolumn{3}{|c|}{$r_{V}=a+b r_{U}+\epsilon$} & \multicolumn{3}{|c|}{$r_{V}=a+b r_{U}+\epsilon, r_{U}<0$} & \multicolumn{3}{|c|}{$r_{V}=a+b r_{U}+\epsilon, r_{U}>0$} \\
\hline & $a$ & $b$ & $R^{2}$ & $a$ & $b$ & $R^{2}$ & $a$ & $b$ & $R^{2}$ \\
\hline CL & $\begin{array}{l}0.000 \\
(-8.379)\end{array}$ & $\begin{array}{l}-0.040 \\
(-1.651)\end{array}$ & 0.014 & $\begin{array}{l}-0.400 \\
(-6.205)\end{array}$ & $\begin{array}{l}-0.163 \\
(-2.964)\end{array}$ & 0.087 & $\begin{array}{l}-0.302 \\
(-5.747)\end{array}$ & $\begin{array}{l}0.013 \\
(0.320)\end{array}$ & -0.000 \\
\hline NG & $\begin{array}{l}-0.221 \\
(-5.284)\end{array}$ & $\begin{array}{l}0.058 \\
(3.017)\end{array}$ & 0.058 & $\begin{array}{l}-0.366 \\
(-5.594)\end{array}$ & $\begin{array}{l}-0.049 \\
(-1.963)\end{array}$ & 0.018 & $\begin{array}{l}-0.547 \\
(-8.026)\end{array}$ & $\begin{array}{l}0.217 \\
(8.997)\end{array}$ & 0.328 \\
\hline SPX & $\begin{array}{c}-0.538 \\
(-16.848) \\
\end{array}$ & $\begin{array}{r}-0.398 \\
(-7.366) \\
\end{array}$ & 0.195 & $\begin{array}{c}-0.571 \\
(-10.848) \\
\end{array}$ & $\begin{array}{r}-0.546 \\
(-8.651) \\
\end{array}$ & 0.193 & $\begin{array}{l}-0.710 \\
(-15.342) \\
\end{array}$ & $\begin{array}{l}-0.043 \\
(-0.346) \\
\end{array}$ & 0.000 \\
\hline
\end{tabular}

Exhibit 14: Relationship between variance swap returns and returns of the underlying asset Notes: $r_{V}$ is the log excess return on a variance swap. $r_{U}$ is the annualized log return on the underlying asset over the life of the swap. $C L$ denotes crude oil, $N G$ denotes natural gas, and $S P X$ denotes the S\&P 500 equity index. The regressions to the left use all available data. The regressions in the middle use only those observations where the return on the underlying asset is negative. The regressions to the right use only those observations where the return on the underlying asset is positive. Regressions are estimated by OLS. The $T$-statistics under the null hypotheses of $a=0$ and $b=0$ are reported in parentheses. These are computed using the Newey and West (1987) estimator with a lag-length equal to the maximum variance swap maturity over the sample (33 business days for CL, 33 business days for NG, and 22 business days for SPX). 

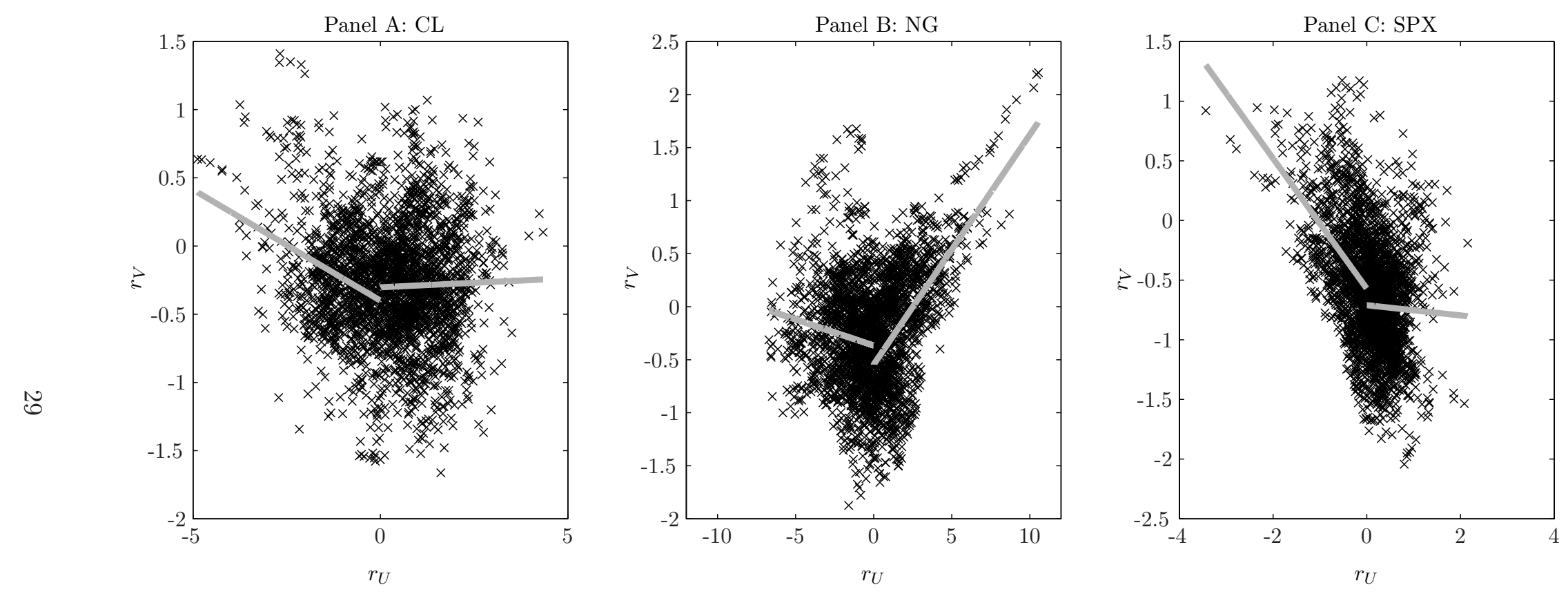

Exhibit 15: Returns on variance swaps vs. returns of the underlying assets

Notes: $r_{V}$ is the $\log$ excess return on a variance swap. $r_{U}$ is the annualized $\log$ return on the underlying asset over the life of the swap. $C L$ denotes crude oil, $N G$ denotes natural gas, and SPX denotes the S\&P 500 equity index. In each panel, the grey line to the left is the regression fit using only those observations where the return on the underlying asset is negative, while the grey line to the right is the regression fit using only those observations where the return on the underlying asset is positive. 


\section{Notes}

${ }^{1}$ See Davis (2006).

2 The S\&P GSCI is comprised of 24 commodities with the weight of each commodity determined by their relative levels of world production over the past five years. The DJAIGCI is comprised of 19 commodities with the weight of each component determined by liquidity and world production values, with liquidity being the dominant factor. In addition, for this index, no single commodity may constitute more than 15 percent and no sector may constitute more than 33 percent. Crude oil and natural gas are the largest components in both indices. In 2007, their weights were 51.30 percent and 6.71 percent, respectively, in the S\&P GSCI and 13.88 percent and 11.03 percent, respectively, in the DJ-AIGCI.

${ }^{3}$ Upon revising the paper, we attempted to extend the sample to 2009. However, NYMEX (now part of CME group) was not able to provide us with the latest data.

${ }^{4}$ The Chicago Board Options Exchange (CBOE) recently introduced a Crude Oil Volatility Index (ticker symbol OVX). This index also measures the conditional risk-neutral expectation of crude oil variance, but is computed from a cross-section of listed options on the United States Oil Fund (ticker symbol USO), which tracks the price of WTI as closely as possible. However, since USO options only started trading in May, 2007, the history of this index is too short to investigate the crude oil variance risk premium.

${ }^{5}$ Bakshi and Kapadia (2003b) also find that variance risk premia for individual stocks are less negative than for the S\&P 500 index.

${ }^{6}$ Carr and $\left.\mathrm{Wu}(2009)\right)$ provide a more general derivation for the case where the underlying asset is a semi-martingale.

${ }^{7}$ See, e.g., Gatheral (2006) p. 137. Whether one computes variance in terms of log returns or arithmetic returns and whether one demeans returns or not, makes little difference to the results.

${ }^{8}$ Crude oil and natural gas trade in units of 1,000 barrels and 10,000 million British thermal units (mmBtu), respectively. Prices are quoted as US dollars and cents per barrel or mmBtu. 
${ }^{9}$ Settlement prices for all contracts are determined by a "Settlement Price Committee" at the end of regular trading hours and represent a very accurate measure of the true market prices at the time of close. Settlement prices are widely scrutinized by all market participants since they are used for marking to market all account balances.

${ }^{10}$ For crude oil, options expire three business days prior to the expiration of the underlying futures contract, which in turn expires on the third business day prior to the 25th calendar day of the month preceding the delivery month (if the 25th calendar day is a non-business day, expiration is on the third business day prior to the business day preceding the 25th calendar day). For natural gas, options expire one business day prior to the expiration of the underlying futures contract, which in turn expires on the third business day prior to the delivery month.

11 NYMEX does list European-style options on both commodities. However, the trading history is much shorter and liquidity is much lower than for the American-style options.

12 The idea is, for each option, to assume that the price of the underlying futures contract follows a geometric Brownian motion. With this assumption, American options can be priced using the Barone-Adesi and Whaley (1987) formula. Inverting this formula for a given American option price yields an implied volatility, from which the associated European option can be priced with the Black (1976a) formula.

13 The CBOE webiste contains the details of the construction.

14 Note that due to missing options data, there are fewer than 2750 observations for the variance swap rates.

15 Since natural gas is also used for electricity generation, higher-than-expected air conditioning demand during the summer due to exceptionally warm weather may also cause sharp increases in natural gas prices.

16 Trolle and Schwartz (2009) estimate various stochastic volatility HJM models on crude oil futures and options data and find small negative correlations in the range -0.10 to 0 between innovations to volatility and spot returns. Since spot returns are very highly correlated with returns on the front futures contract, this is consistent with the correlations found here.

17 This is the so-called "leverage effect", first discussed by Black (1976b), although changes in leverage is probably not the main explanation for the negative correlation - see, e.g., Figlewski 
and Wang (2000).

${ }^{18}$ In case of the S\&P 500 index, the estimated annualized Sharpe ratio is very close to the 0.98 reported by Carr and $\mathrm{Wu}(2009)$.

${ }^{19}$ Note that due to large differences in the standard deviation of the payoff, the mean payoff is statistically insignificant during the cold season but statistically significant during the warm season. In contrast, the mean log excess return is more strongly statistically significant during the cold season than during the warm season. Note also that both the payoff distribution and the log excess return distribution are positively skewed during the cold season, while negatively skewed during the warm season.

20 To see this, let $\widehat{\mu}_{1}$ and $\widehat{\mu}_{2}$ denote the estimated mean payoffs or mean log excess returns during the cold and the warm season, respectively. Furthermore, let $\widehat{\sigma}_{1}^{2}$ and $\widehat{\sigma}_{2}^{2}$ denote the variances estimated with the approach of Newey and West (1987) using 33 lags, and let $n_{1}$ and $n_{2}$ denote the number of observations. Then, under the null-hypothesis of equal means, and assuming independence between the cold and the warm season, we have that

$$
T=\frac{\widehat{\mu}_{1}-\widehat{\mu}_{2}}{\sqrt{\widehat{\sigma}_{1}^{2} / n_{1}+\widehat{\sigma}_{2}^{2} / n_{2}}}
$$

is asymptotically standard normally distributed. When testing for equality between the mean payoffs, we have $T=-0.11$, and when testing for equality between the mean log excess returns, we have $T=-0.51$. Hence, in neither case can we reject the null-hypothesis of equality.

${ }^{21}$ A number of studies (see, e.g., Canina and Figlewski (1993)), using mostly equity data, have run regressions similar to (8) to test the extent to which implied volatility contains information about future realized volatility. These studies generally find $b$ to be significantly less than one, implying that implied volatility is a biased forecast of future realized volatility. While this is consistent with a time-varying volatility risk premium, it is sometimes interpreted as evidence for market frictions or even options trader irrationality.

${ }^{22}$ For the S\&P GSCI, the excess return is computed from the S\&P GSCI Excess Return index which measures the return from investing in nearby S\&P GSCI futures and rolling them forward each month.

23 As already noted by Carr and Wu (2006) and Carr and Wu (2009), it also does not seem to be able to explain the equity index variance risk premium, although the equity index 
variance swap has a significant negative loading on the equity market portfolio.

${ }^{24}$ Another commodity specific factor that has been investigated in the literature is the net position of hedgers in the futures market; see, e.g., Bessembinder (1992) and de Roon, Nijman, and Veld (2000) who link futures risk premia to this factor. In a similar vein, it would be interesting to investigate if energy variance risk premia vary with the net positions of hedgers in the crude oil and natural gas options market. Unfortunately, while the Commodity Futures Trading Commission does publish some information about the net position of hedgers in options markets, this is done on a futures-equivalent basis, which implies that it groups together long call and short put positions as well as long put and short call positions. For our purpose, we would need information about the extent to which hedgers are long calls and puts, and this information is not readily available.

${ }^{25}$ Inventory data for a given week are released by the EIA on the following Wednesday in the case of crude oil and Thursday in the case of natural gas. We therefore match inventories with returns on variance swaps initiated the following Wednesday or Thursday.

${ }^{26}$ For robustness, we also ran the regressions with absolute, rather than relative, inventories but found no significant relationships with variance risk premia. 


\section{References}

Bakshi, G. and N. Kapadia (2003a). Delta-hedged gains and the negative market volatility risk premium. Review of Financial Studies 16, 527-566.

Bakshi, G. and N. Kapadia (2003b). Volatility risk premium embedded in individual equity options: Some new insights. Journal of Derivatives 11, 45-54.

Barone-Adesi, G. and R. Whaley (1987). Efficient analytic approximation of american option values. Journal of Finance 42, 301-320.

Bessembinder, H. (1992). Systematic risk, hedging pressure, and risk premiums in futures markets. Review of Financial Studies 5, 637-667.

Black, F. (1976a). The pricing of commodity contracts. Journal of Financial Economics 3, $167-179$.

Black, F. (1976b). Studies of stock price volatility changes. Proceedings of the 1976 Meetings of the American Statistical Association, Business and Economic Statistics Section 1, $177-181$.

Bollerslev, T., M. Gibson, and H. Zhou (2004). Dynamic estimation of volatility risk premia and investor risk aversion from option-implied and realized volatilities. Working paper, Duke University and Federal Reserve Board.

Bondarenko, O. (2004). Market price of variance risk and performance of hedge funds. Working paper, University of Illinois at Chicago.

Britten-Jones, M. and A. Neuberger (2000). Option prices, implied price processes, and stochastic volatility. Journal of Finance 55, 839-866.

Broadie, M., M. Chernov, and M. Johannes (2007). Model specification and risk premiums: Evidence from futures options. Journal of Finance 62, 1453-1490.

Canina, L. and S. Figlewski (1993). The informational content of implied volatility. Review of Financial Studies 6, 659-681.

Carr, P. and D. Madan (1998). Towards a theory of volatility trading. in, Robert Jarrow, eds.: Risk Book on Volatility, Risk, New York.

Carr, P. and D. Madan (2001). Optimal positioning in derivatives securities. Quantitative Finance 1, 19-37. 
Carr, P. and L. Wu (2006). A tale of two indices. Journal of Derivatives 13, 13-29.

Carr, P. and L. Wu (2009). Variance risk premia. Review of Financial Studies 22, 1311-1341.

Coval, J. and T. Shumway (2001). Expected option returns. Journal of Finance 56, 9831009.

Davis, A. (2006). How giant bets on natural gas sank brash hedge-fund trader. Wall Street Journal September 19.

de Roon, F., T. Nijman, and C. Veld (2000). Hedging pressure effects in futures markets. Journal of Finance 55, 1437-1456.

Demeterfi, K., E. Derman, M. Kamal, and J. Zou (1999). A guide to volatility and variance swaps. Journal of Derivatives 6, 9-32.

Dincerler, C., Z. Khokher, and T. Simin (2006). An empirical analysis of commodity convenience yields. Working paper, Pennsylvania State University.

Doran, J. S. and E. I. Ronn (2008). Computing the market price of volatility risk in the energy commodity markets. Journal of Banking and Finance 32, 2541-2552.

Duarte, J., F. Longstaff, and F. Yu (2007). Risk and return in fixed income arbitrage: Nickels in front of a steamroller. Review of Financial Studies 20, 769-811.

Erb, C. and C. Harvey (2006). The strategic and tactical value of commodity futures. Financial Analysts Journal 62, 69-97.

Figlewski, S. and X. Wang (2000). Is the 'Leverage Effect' a Leverage Effect? Working paper, NYU Stern School of Business.

Gatheral, J. (2006). The Volatility Surface. Wiley.

Gorton, G., F. Hayashi, and G. K. Rouwenhorst (2008). The fundamentals of commodity futures returns. Working paper, Yale University.

Gorton, G. and G. K. Rouwenhorst (2006). Facts and fantasies about commodity futures. Financial Analysts Journal 62, 47-68.

Ibbotson (2006). Strategic asset allocation and commodities. March 2\%.

Jagannathan, R. (1985). An investigation of commodity futures prices using the consumption-based intertemporal capital asset pricing model. Journal of Finance 40, $175-191$. 
Jiang, G. and Y. Tian (2005). The model-free implied volatility and its information content. Review of Financial Studies 18, 1305-1342.

Kat, H. and R. Oomen (2007a). What every investor should know about commodities, Part I. Journal of Investment Management 5, 4-28.

Kat, H. and R. Oomen (2007b). What every investor should know about commodities, Part II. Journal of Investment Management 5, 40-64.

Newey, W. and K. West (1987). A simple, positive semi-definit, heteroscedasticity and autocorrelation consistent covariance matrix. Econometrica 55, 703-708.

Pan, J. (2002). The jump-risk premia implicit in options: Evidence from an integrated time-series study. Journal of Financial Economics 63, 3-50.

Trolle, A. B. and E. S. Schwartz (2009). Unspanned stochastic volatility and the pricing of commodity derivatives. Review of Financial Studies 22, 4423-4461. 